\title{
An overview of biomass thermochemical conversion technologies in Malaysia
}

\begin{abstract}
The rising pressure on both cleaner production and sustainable development have been the main driving force that pushes mankind to seek for alternative greener and sustainable feedstocks for chemical and energy production. The biomass 'waste-to-wealth' concept which convert low value biomass into value-added products which contain high economic potential, have attracted the attentions from both academicians and industry players. With a tropical climate, Malaysia has a rich agricultural sector and dense tropical rainforest, giving rise to abundance of biomass which most of them are underutilized. Hence, the biomass 'waste-towealth' conversion through various thermochemical conversion technologies and the prospective challenges towards commercialization in Malaysia are reviewed in this paper. In this paper, a critical review about the maturity status of the four most promising thermochemical conversion routes in Malaysia (i.e. gasification, pyrolysis, liquefaction and hydroprocessing) is given. The current development of thermochemical conversion technologies for biomass conversion in Malaysia is also reviewed and benchmarked against global progress. Besides, the core technical challenges in commercializing these green technologies are highlighted as well. Lastly, the future outlook for successful commercialization of these technologies in Malaysia is included.
\end{abstract}

Keyword: Biomass; Thermochemical conversion 